\title{
Increased Eddy Activity in the Northeastern Pacific during 1993-2011요
}

\author{
Mengrong Ding, Pengfei Lin, And Hailong LiU \\ State Key Laboratory of Numerical Modeling for Atmospheric Sciences and Geophysical Fluid Dynamics, \\ Institute of Atmospheric Physics, Chinese Academy of Sciences, and College of Earth Science, \\ University of Chinese Academy of Sciences, Beijing, China
}

\section{FEI CHAI}

School of Marine Sciences, University of Maine, Orono, Maine, and State Key Laboratory of Satellite Ocean Environment Dynamics, Second Institute of Oceanography, State Oceanic Administration, Hangzhou, China

(Manuscript received 12 May 2017, in final form 12 September 2017)

\begin{abstract}
The authors study the long-term behaviors of eddy activity in the northeastern Pacific (NEP) and the dynamic mechanism behind them, using the third version of the mesoscale eddy trajectory dataset released by Chelton and Schlax as well as other observation and reanalysis datasets. Both the eddy kinetic energy (EKE) and eddy occurrence number (EON) present prominent increases, with interannual and decadal variabilities northeast of the Hawaiian-Emperor seamounts. The increasing EON is mainly due to the prolongation of eddy lifetimes associated with eddy intensification, particularly for anticyclonic eddies (AEs). The prolongation of eddy lifetimes results from weakened surface winds. The enhanced anticyclonic wind stress curl (WSC) injects more energy into the AEs in the study domain, providing a more suitable environment for their growth. The decadal climate modes, such as the Pacific decadal oscillation (PDO) and the North Pacific Gyre Oscillation (NPGO), may also modulate eddy activity in the NEP by exerting fluctuations in the surface wind system.
\end{abstract}

\section{Introduction}

As a nonnegligible component of the energy cycle of the global oceans, ubiquitous mesoscale eddies play a vital role in transporting mass, salt, heat, and biogeochemical tracers in the ocean (e.g., Bryden and Brady 1989; Stammer 1998; Jayne and Marotzke 2002; Zhang et al. 2014; Griffies et al. 2015), as well as in air-sea interactions (e.g., O'Neill et al. 2003; Small et al. 2008; Frenger et al. 2013; Ma et al. 2015). Along their westward propagating paths, mesoscale eddies not only make a difference to the water mass (e.g., Uehara et al. 2003; Oka and Qiu 2012; Xu et al. 2014) but also impact the largescale circulation (e.g., Nakamura et al. 2004; Kelly et al. 2010; Zhai et al. 2010; Ma et al. 2016). Conversely, eddy

Supplemental information related to this paper is available at the Journals Online website: https://doi.org/10.1175/JCLID-17-0309.s1.

Corresponding author: Dr. Pengfei Lin, linpf@mail.iap.ac.cn; Dr. Hailong Liu, lhl@lasg.iap.ac.cn activities themselves are affected by large-scale circulations and climate variabilities (e.g., Zhang et al. 2001; Qiu and Chen 2010; Shen et al. 2014; Chow et al. 2017).

The midlatitude North Pacific (Fig. 1a), which also has an abundance of eddy activity, is embedded in a strong lateral gradient of wind stress. The two largescale climate modes in the Pacific, the Pacific decadal oscillation (PDO) and the North Pacific Gyre Oscillation (NPGO), present distinct regional spatial patterns over the northeastern Pacific region (Di Lorenzo et al. 2008). Previous studies on the eddy activity over the North Pacific focus mainly on multiyear eddy statistics in the Kuroshio-Oyashio Extension (KOE), the Gulf of California, the Gulf of Alaska, and the subtropical countercurrent region (e.g., Qiu et al. 1999; DiGiacomo and Holt 2001; Henson and Thomas 2008; Iton et al. 2010; Kurczyn et al. 2012; Liu et al. 2012; Xiu et al. 2012; Yang et al. 2013; Cheng et al. 2014; Ji et al. 2017). Cheng et al. (2014), for example, investigate the detailed statistical characteristics of ocean eddies in the North Pacific. Their results also imply that the background currents may influence the eddy pathways. Some of the 

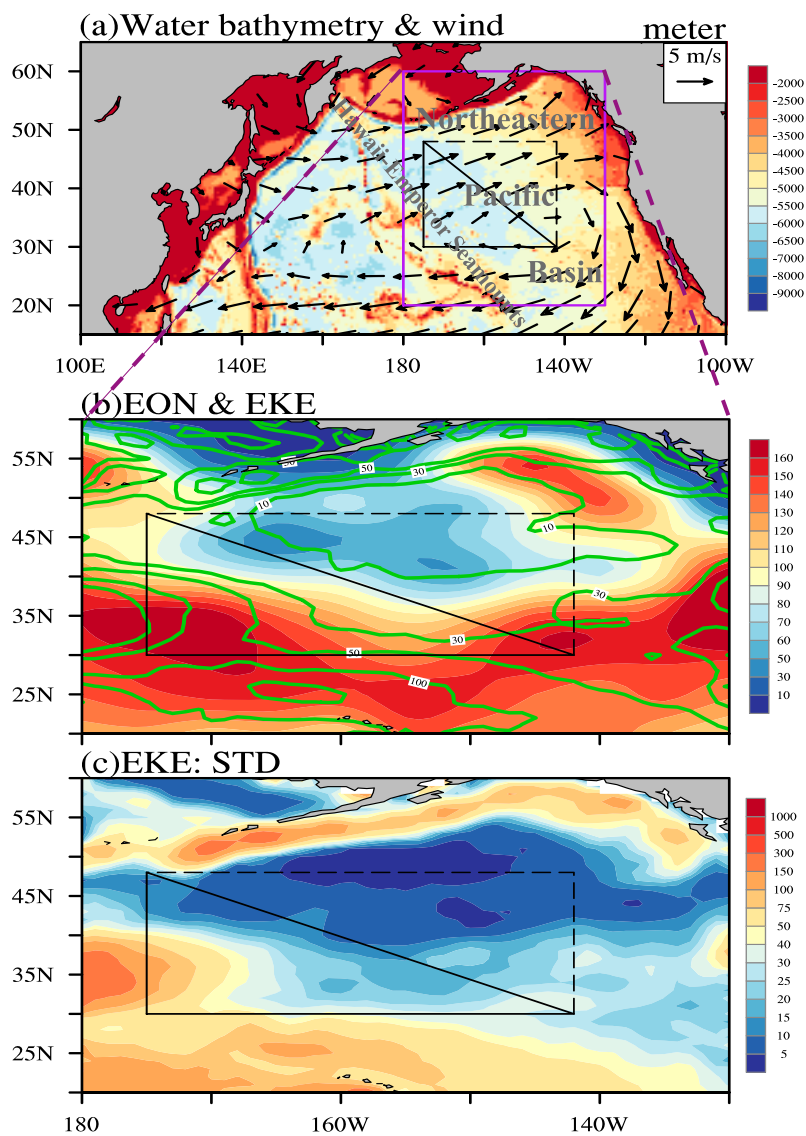

FIG. 1. (a) Bathymetry of the North Pacific basin from the ETOPO5 (shading; $m$ ), and annual average of the ERA-Interim 10-m surface wind field (vectors; $\mathrm{m} \mathrm{s}^{-1}$ ) during 1993-2011. The NEP is denoted by the purple rectangle. (b) Annual average EON (shading) and EKE (contours; $\mathrm{cm}^{2} \mathrm{~s}^{-2}$ ) during 1993-2011. (c) STD $\left(\mathrm{cm}^{2} \mathrm{~s}^{-2}\right)$ of the EKE. The solid triangle denotes our study domain, while the northeastern triangle represents the region known as the eddy desert.

studies report the interannual and decadal variabilities of eddy activities in the North Pacific (Qiu and Chen 2005, 2013; Yoshida et al. 2011; He et al. 2016; Sun et al. 2016; Wang et al. 2016; Chow et al. 2017; Yang et al. 2017). Qiu and Chen (2013) detect that eddy kinetic energy (EKE) within the $18^{\circ}-28^{\circ} \mathrm{N}$ band shows decadally varying signals concurrently, which is correlated with the decadal changes of upper-ocean eastward shear signals. Yang et al. (2017) reveal that the decadal variability of EKE in the KOE region is primarily due to the barotropic flow instability, which is related to the NPGO. However, few studies have focused on the relationship between the long-term variability of eddy activity and large-scale climate modes in the northeastern Pacific (NEP) region $\left(20^{\circ}-60^{\circ} \mathrm{N} ; 180^{\circ}-130^{\circ} \mathrm{W}\right.$, i.e., the purple rectangle in Fig. 1a), where large variances of both the PDO and NPGO happen.
Recent studies on the eddy activity in the Southern Ocean, which is also one of the most eddy-active regions with a strong gradient in wind stress, show that there has been an increase in EKE in recent decades because of continuing increases in the magnitude of the wind stress (Hogg et al. 2015). This result is confirmed by a global high-resolution ocean model in the Antarctic Circumpolar Current domain (Patara et al. 2016). The increasing eddy activity can play a key role in affecting the spatial patterns of ocean circulation and climate. However, except for the Southern Ocean, the long-term variability (including the decadal variability and trend) of eddy activities in other eddy-active regions has not yet been investigated, including the NEP.

To understand the influencing mechanism of largescale climate variability on eddy activities, recent research on air-sea interactions at oceanic mesoscales has uncovered an energetic relationship between the largescale surface wind field and ocean eddies (e.g., Gaube et al. 2015; Byrne et al. 2016; Xu et al. 2016). The damping of eddies by current-induced Ekman pumping cannot be ignored, according to Gaube et al. (2015). They find that the eddy attenuation time scale is inversely proportional to wind speed because of the opposite polarities of the eddy-induced wind stress curl (WSC) and the eddy itself. Using a coupled highresolution atmosphere-ocean model of the South Atlantic, Byrne et al. (2016) suggest that mesoscale ocean eddies could be energized by the thermodynamic pathway through which the large-scale wind field transfers energy into the ocean. Xu et al. (2016) attempt to quantify the work done by the large-scale WSC on ocean eddies using the original and spatially filtered wind stress fields. The results show that the wind field generally injects kinetic energy into the ocean when the background WSC is in the same direction as the eddies, and vice versa. Following these analyses, it is obvious that the work done by the atmospheric wind on ocean eddies undoubtedly has a direct impact on eddy energetics in any eddy-active region.

This study examines the long-term variability of eddy activities in the NEP and the mechanism behind it by using a global mesoscale eddy trajectory dataset. We find that there is a significant increase of eddy activities in the NEP region, which has not been mentioned in previous studies. Furthermore, combined with eddy kinematics, it is found that anticyclonic eddies (AEs), not cyclonic eddies (CEs), dominate the long-term trend of ocean activities in the NEP. A possible physical mechanism of this phenomenon is proposed in the present study. The rest of the paper is organized as follows. The data and methods used in this study are summarized in section 2. In section 3, we present the increases of eddy 
activities in the NEP, followed by a probable physical mechanism for the increases. We also discuss the relations between mesoscale eddy activity and dominant climate decadal modes to interpret the impacts of Pacific decadal modes on eddy activities in the NEP. Finally, a summary is provided in section 4 .

\section{Data and methods}

\section{a. Global mesoscale eddy trajectory dataset}

The mesoscale eddy trajectory dataset version 3.0 for the period from October 1992 to April 2012 (19.5 years in total), released by Chelton and Schlax (2013, hereafter C13), is used in the present study. This dataset was produced via a new threshold-free method of automated eddy identification developed by Chelton et al. (2011). The eddy identification procedure defines mesoscale eddies directly using the sea surface height (SSH) field. This method was applied to avoid noise amplification in the SSH field. Compared with the Okubo-Weiss parameter identification procedure, the SSH-based procedure without the differentiation calculation of the SSH field effectively solves the overestimation issue of eddy identification with less computational load.

The dataset retains only those eddies with lifetimes of four weeks or longer and provides trajectories with 7-day time steps. There are a total of 14789 eddies identified in the NEP region over the whole study period, with $7623 \mathrm{CEs}$ and 7166 AEs. According to the definition in Chelton et al. (2011), eddy amplitude $A_{e}$ is defined as the absolute difference between the SSH extremum value in the eddy interior and the mean height value at the eddy perimeter (defined by the outermost enclosed SSH contour). Eddy radius $R_{e}$ is defined as the radius of a circle covering the same area enclosed by the eddy perimeter. A more detailed description of this dataset can be found at the website http://wombat.coas.oregonstate.edu/eddies_May2013/. Eddy intensity in our study is defined as eddy amplitude over radius $A_{e} / R_{e}$, as proposed by Frenger et al. (2015). We also use another dataset of global mesoscale eddy trajectories produced by Faghmous et al. (2015, hereafter F15) to examine the influence of the input dataset or eddy identification method used and confirm the robustness of our results. A more detailed description of the F15 dataset can be found online at http:// datadryad.org/resource/doi:10.5061/dryad.gp40h.

There are some differences in these two mesoscale eddy trajectory datasets. First, different input datasets were used. F15 used the daily Archiving, Validation, and Interpretation of Satellite Oceanographic (AVISO) sea level anomalies (SLA), which incorporate all the data from available satellite sensors. C13 used the weekly "ref" data that only include data from two simultaneously operating satellite sensors. Besides, the AVISO SLA dataset used by F15 has also been refined by a postproceeding procedure. Second, the eddy identification and tracking methods used are different. The threshold step size used by $\mathrm{C} 13$ is $0.05 \mathrm{~cm}$, while F15 uses fine threshold steps to select an optimum threshold for defining $A_{e}$ and $R_{e}$, and so on. More detailed information about these two mesoscale eddy trajectory datasets can be found in Chelton et al. (2011) and F15.

\section{b. Eddy energetic and kinematic metrics}

In this study, we choose EKE and eddy occurrence number (EON) as the energetic and kinematic metrics, respectively, to describe mesoscale eddy activity.

The weekly altimetry SSH anomaly $\eta^{\prime}$ data used in this study are taken from the AVISO data based on the TOPEX/Poseidon, Jason-1, ERS-1, and ERS-2 data (Ducet et al. 2000), with a horizontal resolution of $0.25^{\circ} \times 0.25^{\circ}$. The EKE, which is defined as $1 / 2\left(U_{g}^{\prime 2}+V_{g}^{\prime 2}\right)$, is calculated using the weekly altimetry SSH anomaly data, where $U_{g}^{\prime}=-(g / f)\left(\partial \eta^{\prime} / \partial y\right)$ and $V_{g}^{\prime}=-(g / f)\left(\partial \eta^{\prime} / \partial x\right)$ are the zonal and meridional geostrophic velocity anomalies, respectively, with $f$ being the Coriolis parameter and $g$ being the gravitational constant. To compare the EKE trends fairly in different grids, the EKE value at each grid is normalized by its standard deviation (STD; shown by Fig. 1c).

In our study, the EON is defined as the sum of all the identified eddies in a $1^{\circ} \times 1^{\circ}$ bin during a period. Here, we choose one season (December-February, MarchMay, June-August, and September-November) to get enough samples (of eddies active in the study domain) as the period for EON. The time period of $\mathrm{C} 13$ begins in October 1992. However, some eddies identified in the study domain during the first few months may have been generated before October 1992. Although starting from the beginning of the dataset will not influence our result about the increasing eddy activity in the NEP, it would be hard to accurately classify these eddies into the three categories we propose in the statements below. With this consideration, we chose the period from spring 1993 to winter 2011 to study the long-term variability of eddy activity in the NEP. Consequently, there are a total of 76 seasons during our study period.

Figure $1 b$ shows the annual distribution of the EKE (contour) and EON (shading), and the spatial distribution pattern is in line with past studies (Chelton et al. 2011; F15). It is obvious that mesoscale eddies can appear nearly everywhere in the NEP, except in the socalled eddy desert, named by Chelton et al. (2007). The magnitude of EKE can quantify the eddy activity from the view point of energetics. The EKE value in a given 
grid is related to how many eddies are in this grid (i.e., the EON) and how strong these eddies are (the eddy intensity). In general, the more eddies present in one region, the larger the EKE is in this region. However, EKE itself cannot distinguish the distinct features of CEs and AEs in the ocean dynamics. By calculating EON based on eddy polarity, associated with the propagating paths of eddies, we can obtain more information, such as eddy origin, eddy lifetime, and so forth. Based on this, the EON can be supposed to relate to the eddy kinematics. Thus, both the EKE and EON can be suitable metrics for representing eddy activities. The combination of EKE and EON is a better way to display eddy activities.

As stated above, the EON is related to eddy lifetime. To establish the relationship of EON with eddy lifetime, we defined the average longitude and average latitude of an eddy as the location of its lifetime. The midst of time of the whole eddy lifetime is considered as the computation time of the eddy lifetime. Then, we averaged all of the eddy lifetimes within a $1^{\circ} \times 1^{\circ}$ bin as the lifetime value for that bin. The analysis of eddy trajectories with a lifetime longer than 12 weeks shows that the majority of eddies active around the study domain had not moved too far away from the study domain after their generation (figure not shown). So we suppose this calculation method of eddy lifetime in a single bin is reasonable.

To further analyze the eddy activity in detail in the study domain, we classify the EON into three categories, which are represented by the schematic diagram (see Fig. S1 in the online supplemental material). The increasing trend of the EON in the study domain can be caused by three processes: an increase in the eddy generation number, an increase in the eddy lasting time in the study domain, and an increase in the number of eddies entering the study domain from the outside. These three processes correspond to three categories and are referred to as generation, existence, and entering in our study, respectively. The black box stands for the study domain. "Generation" suggests that the eddy originates in this study domain. Time 2 and time 1 represent the present and previous time steps of an eddy, respectively. Based on the position change of an eddy from time 1 to time 2, we can classify the eddy into the latter two categories. "Existence" indicates that the eddy in the study domain was already in the study domain at time 1. "Entering" means that the eddy occurred outside of the study domain at time 1, but entered the study domain at time 2 . If the eddy exits the study domain at time 2 , the counting will be stopped at time 2 . The EON classifications of Existence and Entering are calculated from time 2 (i.e., the second week in the eddy lifetime at least). Hereafter, when the terms Generation, Existence, and Entering are set in capital letters like this, it refers to these uses of the terms.

\section{c. Other datasets}

The digital bathymetry, used for the description of topographic features in the North Pacific, is extracted from the global topography of the ETOPO5 on a 5-min latitude-longitude grid (http://www.ngdc.noaa. $\mathrm{gov} / \mathrm{mgg} /$ fliers $/ 93 \mathrm{mgg} 01 . \mathrm{html}$ ). Three sets of monthly data from 1993 to 2012 are used to analyze the largescale background field: 1) a surface wind field at $1^{\circ}$ resolution, distributed by the European Centre for Medium-Range Weather Forecasts (ECMWF) interim reanalysis (ERA-Interim; Dee et al. 2011; downloaded from http://apps.ecmwf.int/datasets/data/ interim-full-moda/levtype $=\mathrm{sfc} /$ ); 2) a global gridded ocean temperature dataset based on latest version of the Met Office Hadley Centre EN series of datasets, EN4, for the upper $2000 \mathrm{~m}$ of the ocean at $1^{\circ}$ resolution (Good et al. 2013, downloaded from http://hadobs.metoffice.com/en4/ download-en4-1-1.html); and 3) a sea level pressure (SLP) dataset with $2^{\circ} \times 2^{\circ}$ resolution, taken from the International Comprehensive Ocean-Atmosphere Dataset (ICOADS; Freeman et al. 2017; https://www. esrl.noaa.gov/psd/data/gridded/data.coads.2deg.html). Last, the PDO index (http://research.jisao.washington. edu/pdo/PDO.latest) and the NPGO index (http://www. o3d.org/npgo/npgo.php) are also used in this study to analyze the relevance between the decadal Pacific modes and ocean eddy activity in the NEP.

\section{Results}

\section{a. The increasing trend of eddy activity in the NEP}

Figure 2a shows the linear trend of normalized EKE from 1993 to 2011, in which the areas with hatch marks indicate the linear trend exceeding the $95 \%$ confidence level. It is apparent that the normalized EKE shows a significant increase between $30^{\circ}$ and $55^{\circ} \mathrm{N}$. The largest patches of significant values occur in $30^{\circ}-48^{\circ} \mathrm{N}, 175^{\circ}-$ $142^{\circ} \mathrm{W}$, which is highlighted by the rectangle. It is worth noting that the linear trend of EKE is increasing with significance, but with relatively small values (Fig. S2). The difference of the linear trends in Figs. S2a and S2b for the study domain is due to the difference of EKE STD, which is larger $\left(\sim 100 \mathrm{~cm}^{2} \mathrm{~s}^{-2}\right)$ in the southwestern part of the study domain and smaller $\left(\sim 10 \mathrm{~cm}^{2} \mathrm{~s}^{-2}\right)$ in the northeastern part (shown by Fig. 1c). To emphasize the increasing eddy activity in the study domain, we chose to use the linear trend of normalized EKE, instead of the trend of EKE itself. In the following, we choose the solid triangle region as our study domain because the 

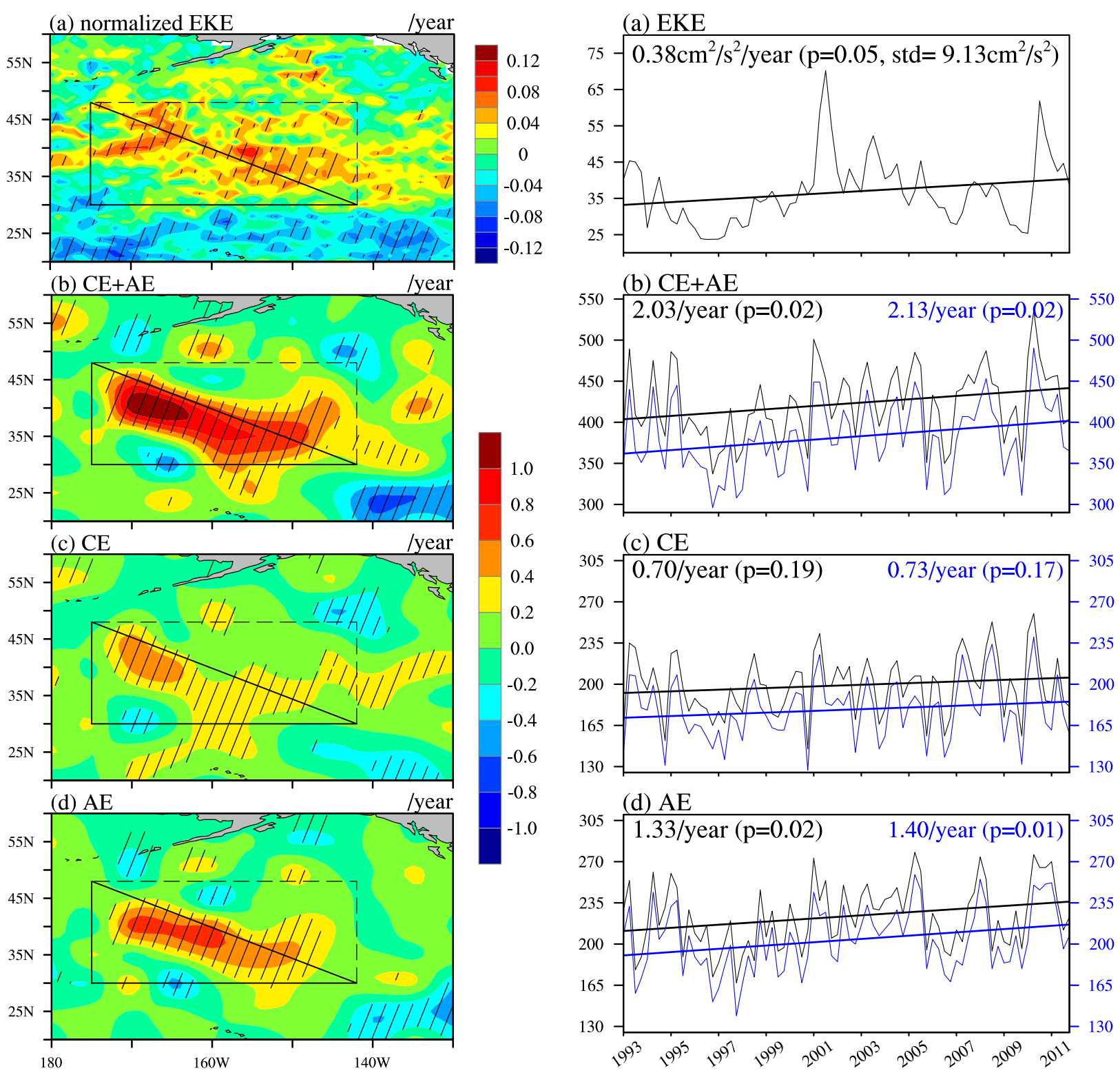

FIG. 2. The linear trends $\left(\mathrm{yr}^{-1}\right)$ of (a) normalized EKE, (b) EON, (c) CEON, and (d) AEON from 1993 to 2011. The hatched areas indicate the linear trend exceeding the $95 \%$ confidence level.

trend of the EON also has a larger value in this region (Fig. 2b). The regionally averaged EKE in the study domain shows a striking linear trend $(p=0.05)$ of approximately $0.38 \mathrm{~cm}^{2} \mathrm{~s}^{-2} \mathrm{yr}^{-1}$ during this period (Fig. 3a). In addition to the long-term increases, variabilities at the interannual and decadal time scales with an STD of $9.13 \mathrm{~cm}^{2} \mathrm{~s}^{-2}$ are also found. The most evident peaks occurred around 2001 and 2010, which were a La Niña year and a transition from El Niño to La Niña year, respectively. In 2008, also a La Niña year, the EKE had no such obvious peak. This suggests that the EKE in the

FIG. 3. Time series of regionally averaged (black curves) (a) EKE, (b) EON, (c) CEON, and (d) AEON from 1993 to 2011. The blue curves denote the regionally averaged existence number of eddies for (b) all eddies, (c) CEs, and (d) AEs. The STD of the regionally averaged EKE is noted in (a). Linear fitting lines of the time series are plotted, and the trends are also noted, with the $p$ values in parentheses; the $95 \%$ confidence level is exceeded when $p$ values are $<0.05$.

study domain may have obvious decadal variability, which indicates that the eddy activities in this region might be affected not only by interannual climate modes but also by decadal modes, which will be further discussed in the following analyses.

As we mentioned above, the magnitude of EKE is associated with both the EON and the intensity of eddies, so the trends of the EON and eddy intensity are 
TABLE 1 . The mean values and trends $\left(\mathrm{yr}^{-1}\right)$ of eddy numbers, amplitudes $A_{e}$, and radii $R_{e}$ for three kinds of eddy occurrence in the study domain from 1993 to 2011. The values in the parentheses are the $p$ values, and the boldface indicates the linear trend exceeding the $95 \%$ confidence level.

\begin{tabular}{|c|c|c|c|c|c|c|c|}
\hline \multirow[b]{3}{*}{ Property } & & \multicolumn{6}{|c|}{ Classification } \\
\hline & & \multicolumn{2}{|c|}{ Generation } & \multicolumn{2}{|c|}{ Existence } & \multicolumn{2}{|c|}{ Entering } \\
\hline & & $\mathrm{CE}$ & $\mathrm{AE}$ & $\mathrm{CE}$ & $\mathrm{AE}$ & $\mathrm{CE}$ & $\mathrm{AE}$ \\
\hline \multirow[t]{2}{*}{ Number } & Mean & 17 & 15 & 178 & 203 & 4 & 5 \\
\hline & Trend & $-0.09(0.31)$ & $-0.17(0.05)$ & $0.73(0.17)$ & $1.40(0.01)$ & $0.05(0.23)$ & $0.10(0.02)$ \\
\hline \multirow[t]{2}{*}{ Amplitude $(\mathrm{cm})$} & Mean & 2.82 & 2.97 & 3.71 & 4.20 & 2.07 & 2.83 \\
\hline & Trend & $0(0.92)$ & $0(0.70)$ & $0(1)$ & $0.03(0.01)$ & $0.03(0.11)$ & $0.05(0.05)$ \\
\hline \multirow[t]{2}{*}{ Radius (km) } & Mean & 77.88 & 75.31 & 84.77 & 84.55 & 59.43 & 63.77 \\
\hline & Trend & $-0.11(0.42)$ & $-0.13(0.37)$ & $0.19(0.03)$ & $0.17(0.04)$ & $-0.01(0.98)$ & $1.02(0.03)$ \\
\hline
\end{tabular}

also investigated. We find that it is the trend of EON, not the eddy intensity (figure not shown), that presents a more similar and significant increasing pattern in our study domain. The pattern of increasing EON does not match exactly with that of the normalized EKE; however, the study domain we chose shows both outstanding increases of normalized EKE and EON. The largest positive trend $\left(>1 \mathrm{yr}^{-1}\right)$ of EON appears near $40^{\circ} \mathrm{N}$, $165^{\circ} \mathrm{W}$ (Fig. 2b). The larger EON trend tilts from northwest to southeast, just along the southwest boundary of the "eddy desert" (the northeastern triangle in Fig. 1b). The comparison between the cyclonic EON (CEON) and anticyclonic EON (AEON) shows that the trend of AEON makes a much greater contribution to the increasing trend of EON in the study domain (Figs. 2c,d). The black lines in Figs. 3b-d are the time series of regionally averaged EON, CEON, and AEON in the study domain during the study period. The linear trends are 2.03, 0.70, and 1.33 per year for the EON, CEON and AEON, respectively. The trend of CEON is the only one that does not exceed the $95 \%$ confidence level. These significant trend values further indicate that increasing AEON dominates the increasing EON. An analogous increase in eddy activity in a similar region can be found in F15 (Fig. S3), suggesting that the increasing eddy activity in the NEP does not depend on the input dataset or eddy identification method used. Therefore, we will focus on the statistical results from $\mathrm{C} 13$ in the following figures.

We suppose that the increases of EON in the study domain may explain much of the increase of the EKE, since it is the EON not the eddy intensity that has shown significant increases in our study domain. According to the definitions of the three categories of EON in section $2 \mathrm{~b}$, we calculate their trends, as well as their kinetic properties $\left(A_{e}\right.$ and $\left.R_{e}\right)$ for the three categories (Table 1$)$. Approximately $90 \%$ of the eddies in the study domain already have existed in the previous season (Table 1). The categories of Generation and Entering represent less than $10 \%$ and $2 \%$ of the EON, respectively. The results are also true for both CEs and AEs. Therefore, the category of Existence accounts for a considerable proportion of the EON in the study domain.

The category Existence also has the largest positive linear trend, which is approximately 14 times larger than that of Entering. Meanwhile, the trend of Generation is negative, which indicates a decrease in the eddy generation number in the study domain. Moreover, the comparison between the Existence of CEs and that of AEs shows that the trend of AE Existence is significant and larger than that of CE Existence. The blue curves in Figs. 3b-d show the time series of Existence averaged in the study domain. The numbers are slightly smaller than the EON (the black curves), but these two curves have similar tendencies. The least squares fitting lines of Existence and EON are almost parallel to each other in Figs. 3b-d, which suggests that the trend of Existence dominates the trend of the EON. Furthermore, the trends of Existence for all eddies and for the AEs exceed the $95 \%$ confidence level, while the trend of CE Existence does not (Table 1). This also indicates that the increase of AEs contributes more than that of CEs.

Existence is related to eddy lifetime and its propagation distance/speed. Thus, to further investigate the trend of eddy activity, the linear trend of eddy lifetime (defined in section 2b) is also illustrated (Fig. 4). It is quite obvious that there is a remarkable increase of eddy lifetime in the study domain. The spatial patterns of the trend values are the same as those of the EONs (Figs. 2b-d). The trend value of AE lifetime exhibits a greater contribution to the prolongation of total eddy lifetime than that of CE lifetime, which is the same as the trends of the AEON and AE Existence.

Note that the Existence eddies have both larger $A_{e}$ and $R_{e}$ than the Generation eddies and Entering eddies (Table 1). The mean $A_{e}\left(R_{e}\right)$ of Existence eddies is 3.71 and $4.20 \mathrm{~cm}(84.77$ and $84.55 \mathrm{~km})$ for CEs and AEs, respectively, while the $A_{e}\left(R_{e}\right)$ values of the other two categories are all less than $3 \mathrm{~cm}(80 \mathrm{~km})$. The positive relationship between eddy lifetime and $A_{e} / R_{e}$ has 


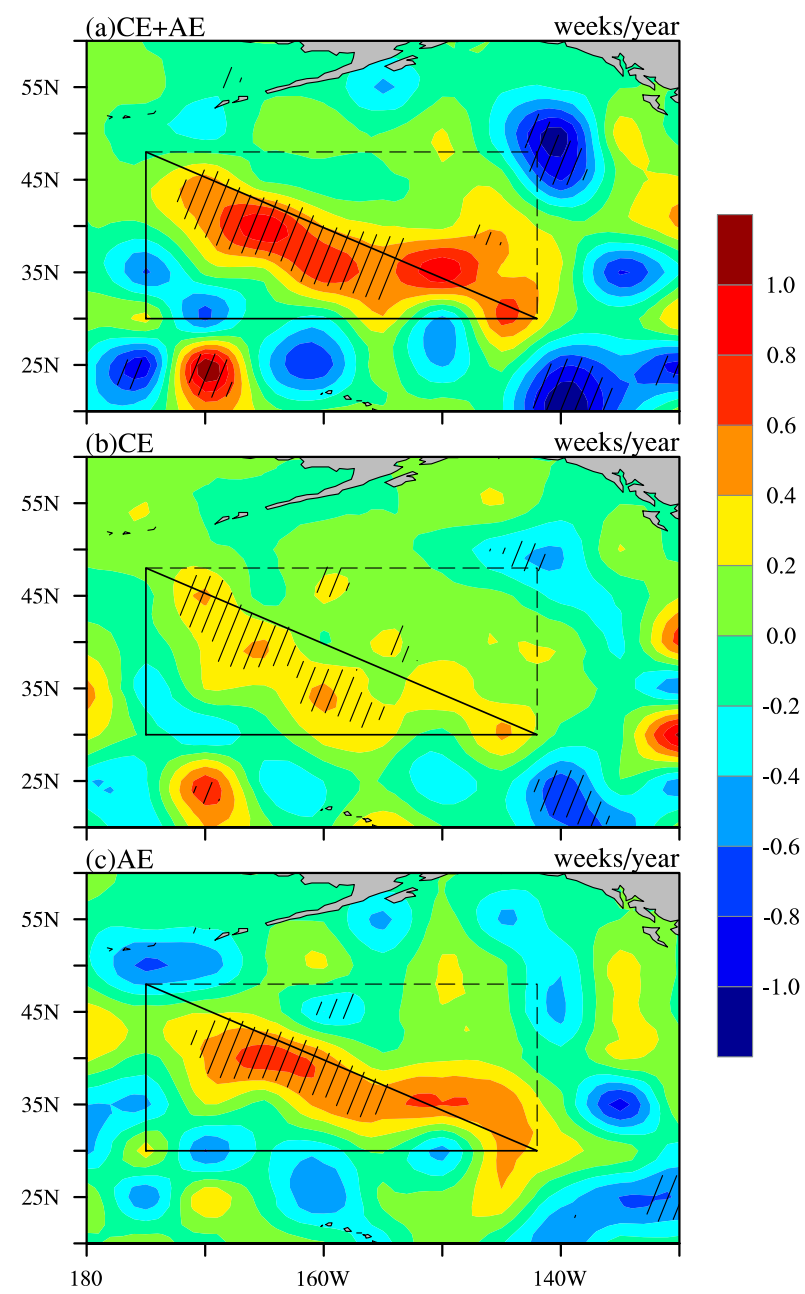

FIG. 4. Linear trends of eddy lifetime (weeks $\mathrm{yr}^{-1}$ ) for (a) all eddies, (b) CEs, and (c) AEs from 1993 to 2011. The hatched area indicates the linear trend exceeding the $95 \%$ confidence level.

already been mentioned in previous studies; that is, the larger and stronger eddies tend to have a longer lifetime (e.g., Chelton et al. 2011). Thus, we can infer that the increasing trend of the EON is mainly due to the prolongation of eddy lifetime, accompanied by both increasing $A_{e}$ and $R_{e}$, particularly for the AEs.

Figure 5 shows the time evolution of $A_{e}$ and $R_{e}$ of the eddies after their initial appearances in the study domain. For simplicity, we define the week when an eddy first appears in the study domain as the "Appearance time" and the period during which an eddy remains in the study domain is defined as the "Existing time." The $A_{e}$ and $R_{e}$ in the Appearance time are recorded as $A_{0}$ and $R_{0}$, respectively. The values in Fig. 5 are ratios of $A_{e}$ and $R_{e}$ to $A_{0}\left(R_{0}\right)$. We have investigated the numbers of CEs and AEs for computing the average in Fig. 5. We find that the eddy numbers are reduced rapidly for both AEs and CEs, with only 23 for AEs and 10 for CEs when
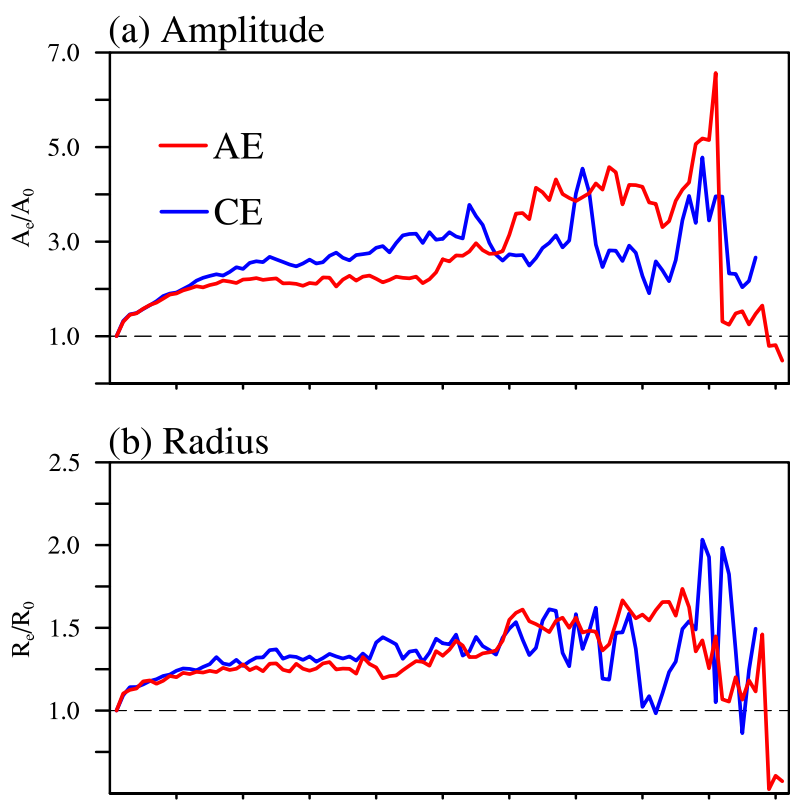

(c) Number of eddies

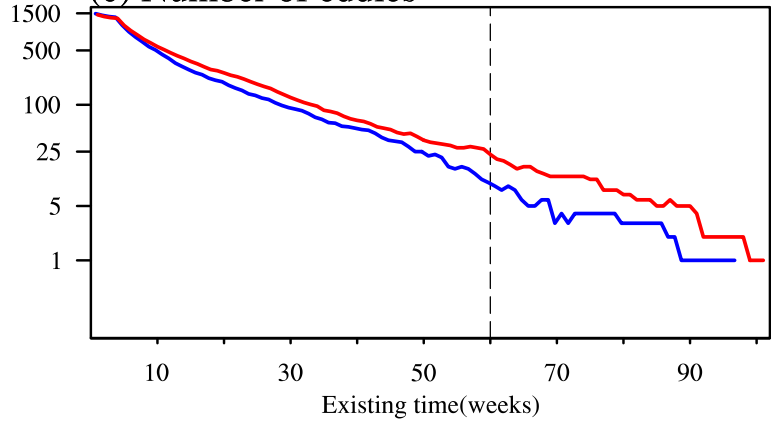

FIG. 5. The ratios of (a) $A_{e}$ and (b) $R_{e}$ to their respective values when eddies first appear in the study domain, i.e., $A_{0}$ and $R_{0}$, for the period when the eddies stay in this area. (c) The eddy numbers appearing in the study domain for the period when the eddies stay in this area. The solid red and blue curves are for AEs and CEs, respectively. The dashed black line in (a) and (b) represents the ratio value of 1 , and the dashed black line in (c) represents an Existing time of 60 weeks.

the Existing time is as long as 60 weeks. Thus, the ratio values (Existing time $>60$ weeks) have large uncertainties due to not having enough eddy numbers. Therefore, it is not important to discuss the values for an Existing time of longer than 60 weeks. The values for Existing time $<60$ weeks are our focus here. In addition, the $A_{0}$ for CEs is smaller than that for AEs (figure not shown). That is why the ratios for CEs are larger than that for AEs in Fig. 5a. We find that the eddies clearly become intensified (the ratio exceeds 1 ) after they first appear in the study domain. Meanwhile, the intensification is more distinct when the Existing time becomes longer, especially for AEs (the red curves). This suggests that there are probably some dynamic mechanisms that affect eddy dissipation or 
intensification, thereby prolonging the lifetime of an eddy in the study domain.

\section{b. Mechanism of the increasing eddy activity in the NEP}

There are a few candidates for the dissipation of eddy energy: 1) bottom friction dissipation, 2) interaction with the internal wave field, 3) continental margin scattering/absorption, and 4) suppression by wind work (Ferrari and Wunsch 2009). Considering that the seabed depth in the study domain is over $5500 \mathrm{~m}$ while the vertical extent of an eddy is approximately $200-1000 \mathrm{~m}$ according to previous studies (Chaigneau et al. 2011; Pegliasco et al. 2015; Yang et al. 2015), eddy dissipation by bottom friction is not likely. Interaction with the internal wave field is more important in areas with strong currents, and the study domain is in the open ocean without strong currents. As shown in Fig. 1a, the study domain is in the open ocean, so the third possibility is also ruled out. As a result, suppression by wind work seems the most likely candidate influencing the eddy dissipation in the study domain. It has been widely recognized that the work done by wind on ocean eddies could have a direct impact on eddy energetics (Zhai et al. 2010; Xu et al. 2016). Therefore, we will focus on examining the direct work done by the local wind field next.

There is surface easterly wind south of $30^{\circ} \mathrm{N}$ and southwesterly wind north of $35^{\circ} \mathrm{N}$ in the NEP (Fig. 1a), accompanied by an anticyclonic WSC south of $35^{\circ} \mathrm{N}$, which is favorable for the generation and maintenance of AEs. Figure 6a shows the linear trend of surface wind speed seasonal anomalies. Obviously, in the study domain there is a decreasing trend of surface wind speed, while there are increasing trends in both the northern and southern regions of the study domain. Such spatial trend structures will cause the anticyclonic WSC along $35^{\circ} \mathrm{N}$ to increase. Based on a simple vertically integrated barotropic vorticity balance, Gaube et al. (2015) determined that the eddy attenuation time scale is inversely proportional to wind speed due to the opposite polarities of the current-induced WSC and the eddy. The eddy attenuation time scale $T_{e}$ can be defined as $T_{e} \sim 2 \rho_{o} D / 3 \rho_{a} C_{D} U_{a}$. Note that $T_{e}$ depends on the density of surface seawater $\rho_{o}=1020 \mathrm{~kg} \mathrm{~m}^{-3}$, the density of surface air $\rho_{a}=1.2 \mathrm{~kg} \mathrm{~m}^{-3}$, the vertical scale of the mesoscale eddy $D$ [the vertical extent of the eddy may be approximately $200-1000 \mathrm{~m}$ according to the studies of other regions (e.g., Chaigneau et al. 2011; Pegliasco et al. 2015; Yang et al. 2015); note that almost no analysis is available on the three-dimensional structure of ocean eddies in the NEP], the drag coefficient $C_{D} \sim O\left(10^{-3}\right)$, which is related to wind speed and surface roughness,

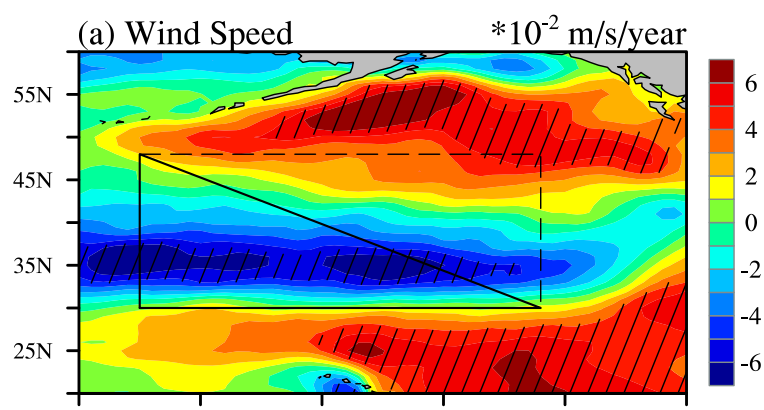

(b) 1993-1997

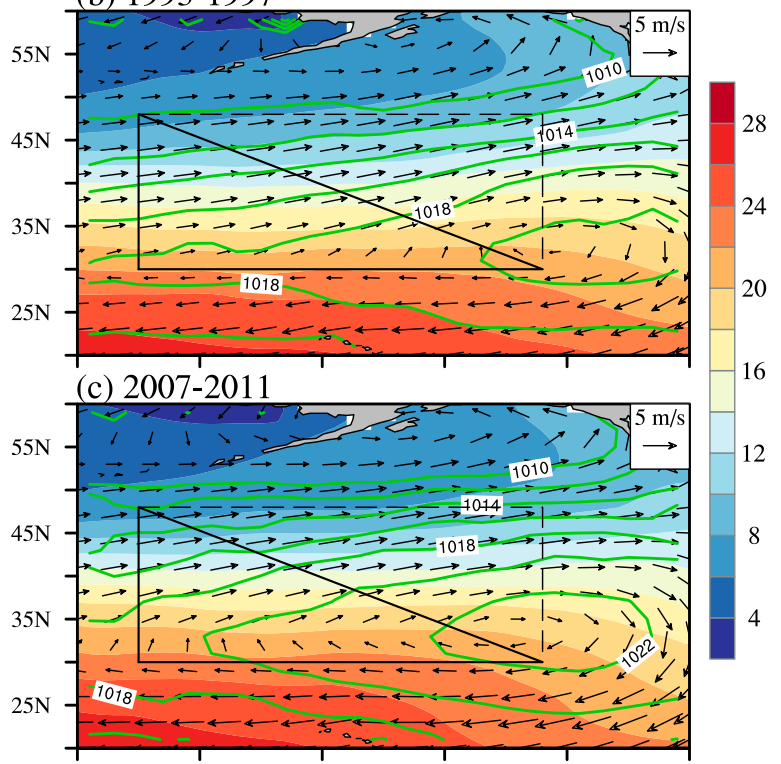

(d) Difference

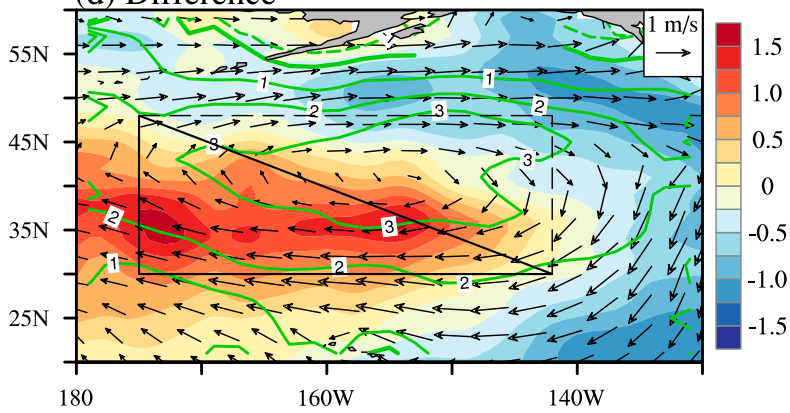

FIG. 6. (a) Linear trend of ERA-Interim 10-m wind speed seasonal anomalies $\left(\mathrm{m} \mathrm{s}^{-1} \mathrm{yr}^{-1}\right)$. The hatched area represents the linear trend exceeding the $95 \%$ confidence level. Annual average of the sea surface temperature field from EN4.1.1 (shading; ${ }^{\circ} \mathrm{C}$ ), sea level pressure (contours; $\mathrm{hPa}$ ) from the ICOADS dataset, and ERA-Interim 10-m wind field (vectors; $\mathrm{m} \mathrm{s}^{-1}$ ) for (b) 1993-97 and (c) 2007-11. (d) Difference between 2007-11 and 1993-97.

and wind speed $U_{a}$. Here, we assume that $\rho_{o}, \rho_{a}, C_{D}$, and $D$ are constants to simplify the calculations. Thus, $T_{e}$ depends only on wind speed $U_{a}$. If we denote $\Delta U=U_{1}-U_{2}$ as the wind speed difference between $T_{1}$ (the spring of 1993 in our study) and $T_{2}$ (the winter of 2011 in our study), the eddy attenuation time scale difference can be 
estimated by solving $\Delta U / U_{2} \sim\left(U_{\text {trend }} \times T\right) / U_{2}$ (where $U_{\text {trend }}$ represents the trend of the wind speed $T=T_{2}-T_{1}$ ). The regionally averaged trend of the wind speed is $0.05 \mathrm{~m} \mathrm{~s}^{-1} \mathrm{yr}^{-1}$ in the study domain, and the regionally averaged wind speed is approximately $4 \mathrm{~m} \mathrm{~s}^{-1}$ at $T_{2}$ (here, the time-averaged wind speed in the study domain is chosen); the eddy attenuation time scale would be lengthened by more than $1.2 \% \mathrm{yr}^{-1}(12 \%$ decade $^{-1}$ ) according to the calculation. Considering that the regionally averaged eddy lifetime and the trend of eddy lifetime in the study domain are approximately 18 weeks and 0.3 weeks yr ${ }^{-1}$ respectively, the percentage of change in eddy lifetime is approximately $1.7 \% \mathrm{yr}^{-1}\left(17 \%\right.$ decade $\left.^{-1}\right)$. This result is similar to, although slightly larger than, the estimate of the change in the eddy attenuation time scale $(12 \%)$. Actually, the eddy attenuation time scale will be further increased since $C_{D}$ will decrease as the wind speed decreases, rather than remaining constant as was assumed. Based on the above calculation, we speculate that the decreasing wind speed in the study domain tends to prolong the lifetimes of ocean eddies and results in the increasing trend of eddy activity in the NEP.

Besides calculating the linear trend, we also study the difference between the first and last five years of our study period to illustrate the increase in eddy activity. The comparison of SLP shows higher pressure during 2007-11 than during 1993-97 over the NEP (Figs. 6b,c). The higher pressure coincides with the warm sea surface temperature anomalies during 2007-11 (the SST data are only used in Fig. 6). This caused the increase in the anticyclonic wind anomalies between these two periods (Fig. 6d). These anomalies were centered on $40^{\circ} \mathrm{N}, 155^{\circ} \mathrm{W}$ and over $25^{\circ}-50^{\circ} \mathrm{N}, 180^{\circ}-140^{\circ} \mathrm{W}$, which would induce anticyclonic WSC anomalies. Xu et al. (2016) note that the wind generally injects kinetic energy into the AEs in the subtropical gyres since the background anticyclonic WSC induces the same vorticity as the AEs. Thus, the anticyclonic WSC anomalies can inject energy into the AEs and strengthen the AEs in the study domain. This result partially explains why the increasing trend of AEs contributes more to the increasing trend of eddy activity than that of CEs in the NEP during 1993-2011.

\section{c. Decadal variability of eddy activity in the NEP}

From the discussion above, the eddy activity in the study domain (for both EKE and EON) shows not only a significant increasing trend but also obvious interannual and decadal variabilities, with larger values in 2001 and 2010 (Fig. 3). Here, we further investigate the relationship between eddy activity and the dominate climate modes in the North Pacific, namely the PDO and NPGO

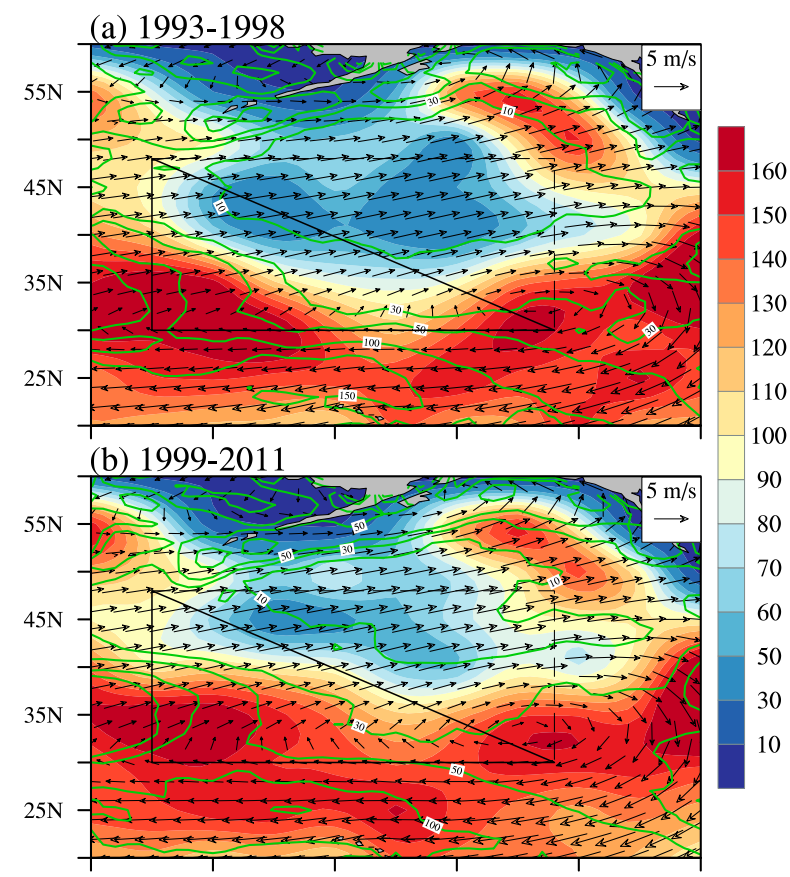

(c) Difference

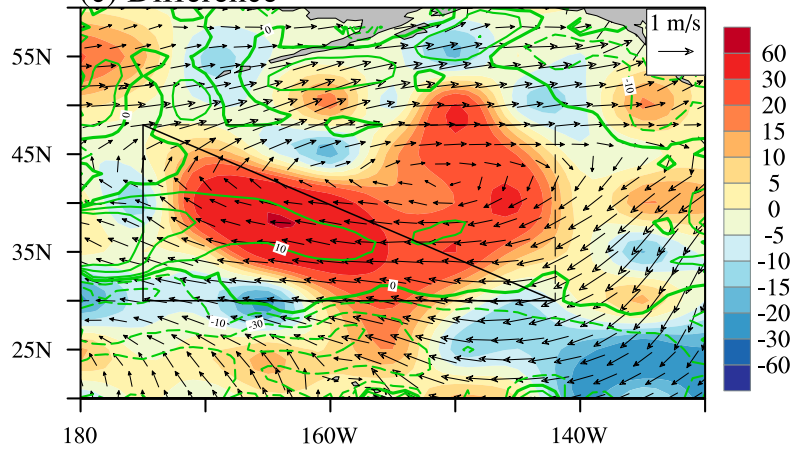

FIG. 7. Annual average of the EON (shading), EKE (contours; $\mathrm{cm}^{2} \mathrm{~s}^{-2}$ ), and ERA-Interim 10-m wind field (vectors; $\mathrm{m} \mathrm{s}^{-1}$ ) for (a) 1993-98 and (b) 1999-2011. (c) Difference between 1999-2011 and 1993-98.

(Mantua and Hare 2002; Bond et al. 2003; Rayner et al. 2003; Di Lorenzo et al. 2008; Newman et al. 2016). Considering that the PDO shifted from a warm phase to a cold phase around the mid-1990s (the year 1998 is regarded as a transition year), we conduct a composite analysis of the EKE, EON, and surface wind during 1993-98 and 1999-2011 (Fig. 7). It is clear that the southern edges of the eddy desert shifted northward, as shown in both EKE and EON distributions, during 1999-2011. At the same time, the easterlies wind belt also shifted northward. The changes are clearly shown in the difference plot (Fig. 7c), in which there are positive $\mathrm{EKE} / \mathrm{EON}$ anomalies and easterly wind anomalies in our study domain. According to Di Lorenzo et al. (2008), both the cold PDO phase and the warm NPGO phase show similar easterly wind anomalies in the study 
domain. Combined with the dynamic mechanism we proposed about the increases of eddy activity, we believe that both the cold PDO phase and the warm NPGO phase may modulate the eddy activity in the study domain via wind stress through the same mechanism. This result suggests that the variation of the eddy activity may also be modulated by the NPGO.

To examine decadal variation, the lead and lag correlation coefficients between the 4-yr low-pass-filtered regionally averaged EKE and EON and PDO (blue curve) and NPGO (red curve) index are calculated for the study domain (Fig. 8). Those lead and lag correlation coefficients using the unfiltered time series were also significant, but with relatively smaller values. It is obvious that the 4-yr low-pass-filtered regionally averaged EKE and EON are significantly negatively correlated with the PDO index, with a lag coefficient of approximately 23 years, and positively correlated with the NPGO index, with a lag coefficient of approximately $1-3$ years, particularly for the AEs. Moreover, the correlations remain significant even after the regionally averaged EKE and EON have been detrended. This suggests that the eddy activity in the NEP is indeed influenced by these Pacific decadal modes, namely the PDO and NPGO.

The large-scale structures of the PDO and NPGO suggest that their underlying dynamics drive the spatial decadal fluctuations in the wind field across the Pacific Ocean (Di Lorenzo et al. 2008). The cold PDO phase has higher pressure over the NEP, with warm temperature anomalies and anticyclonic wind anomalies, which are conducive to the growth of AEs, as we discussed above. During the positive phase of the NPGO, anticyclonic wind stress anomalies exist south of the North Pacific Current (NPC), which similarly provide a more suitable environment for $\mathrm{AE}$ activity in the study domain. Meanwhile, both observations and models support the notion that the transient EKE is basically controlled by the local wind stress at a time scale $<5$ years (Meredith and Hogg 2006; Screen et al. 2009; Hogg et al. 2015). This may explain the significant $1-3$ years' lead relations between the PDO/NPGO index and eddy activity.

In addition, we noticed that the EKE (and EON) has a higher correlation with the NPGO than with the PDO. We suspect that it is related to the intensification of the NPC during the positive phase of the NPGO. According to the study of Di Lorenzo et al. (2008), the first and second empirical orthogonal function (EOF) spatial patterns of SSH anomalies are distinct; furthermore, the SSH anomalies can be assumed as the change of geostrophic flow. The EOF2 of SSH anomalies representing the NPGO mode is shown by the dipole structure separated by the NPC flow along $40^{\circ} \mathrm{N}$. As previously mentioned, Existence is also related to the propagation
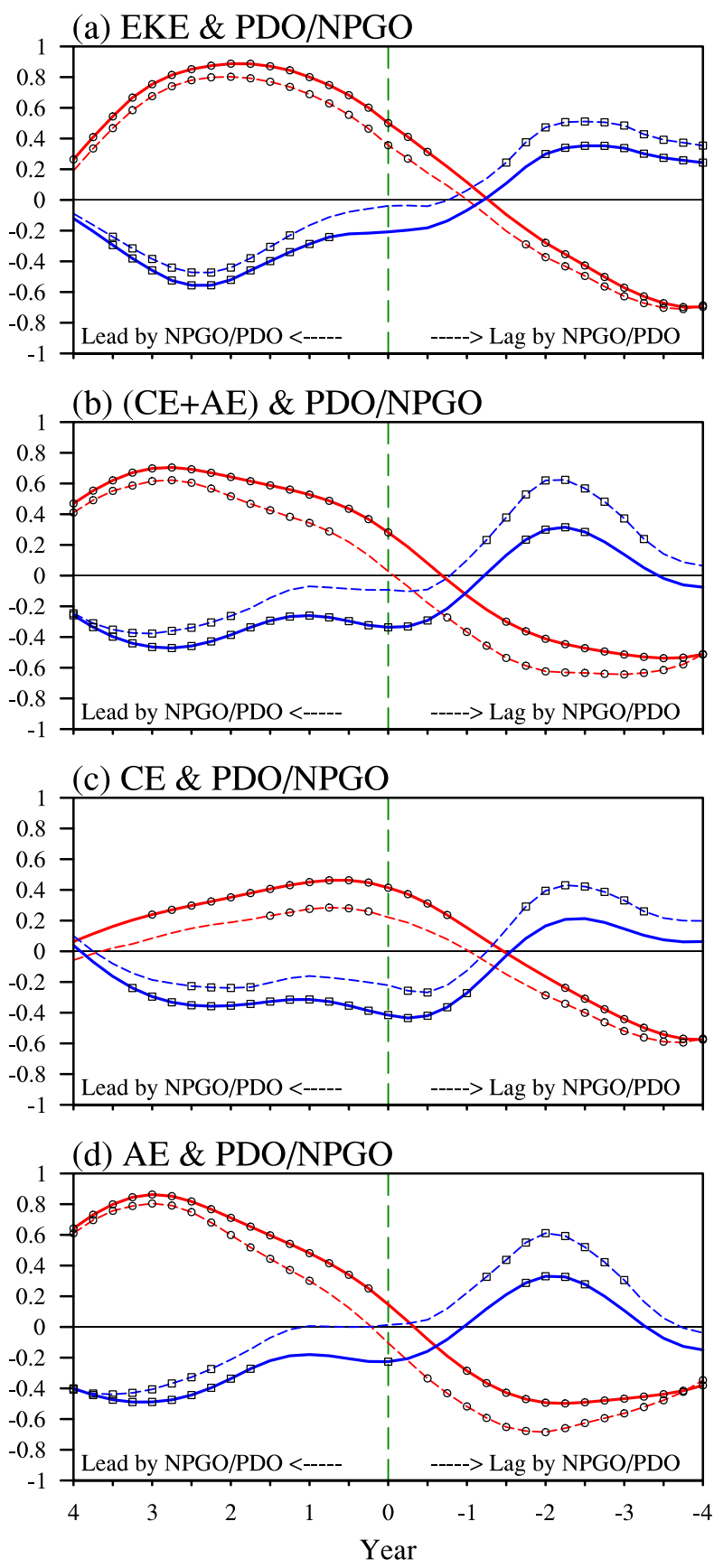

FIG. 8. (a) The lead and lag correlation coefficients between the NPGO (red lines) or the PDO (blue lines) index and the 4-yr lowpass-filtered regionally averaged EKE time series with linear trend (solid lines) or without linear trend (dashed lines) in the study domain. (b)-(d) As in (a), but for EON, CEON, and AEON, respectively. The circles and squares represent the correlations that exceed the $95 \%$ confidence level. The dashed vertical green line represents zero.

distance and moving speed of the eddies. Under this circumstance, the intensification of the NPC may influence the typical pathway and westward transport of ocean eddies in the study domain after 2-3 years of positive 
NPGO forcing. Maybe that is why the NPGO has a higher correlation with the 4-yr low-pass-filtered regionally averaged EKE/EON in the study domain in Fig. 8.

In conclusion, the eddy activity in the NEP demonstrates obvious decadal variability that is due to the decadal fluctuation in the wind field under the influence of the PDO and NPGO. According to previous studies (Di Lorenzo et al. 2008; Sydeman et al. 2013; Newman et al. 2016), the NPGO has been intensified by global warming, whereas the PDO has shifted to the cold phase during the twenty-first century. Thus, it is highly likely that the eddy activity in the NEP will further increase under global warming or climate shifts, especially the AEs in the study domain.

\section{Summary}

In the present study, a 19.5-yr time series of the mesoscale eddy trajectory dataset is used to study the longterm, continuous eddy activity in the NEP. Both the EKE and EON in the northeastern region of the Hawaiian-Emperor seamounts present significant increases, along with interannual and decadal variabilities. The increases of eddy lifetime, particularly for AEs, presents a spatial pattern similar to the trend of the EON in the study domain, which means that the increase in eddy lifetime is the primary contributor to the increase in EON. The eddy lifetime prolongation is due to eddy intensification in the study domain.

The weakening trend of the surface wind can explain the prolongation of eddy lifetime. The eddy attenuation time scale is inversely proportional to the surface wind speed; therefore, the prolongation of eddy lifetime is related to the weakened trend of wind speed over the study domain, regardless of AEs or CEs. The enhanced anticyclonic WSC anomaly is found to provide a more suitable environment for the growth of AEs since the background WSC is in the same direction as that of AEs, which results in more energy being injected into the AEs. This result partially explains why the increasing trend of AEs contributes more to the increasing trend of eddy activity than that of CEs in the NEP during 19932011. The weakened wind speed (associated with the change in SLP) in the study domain is possibly due to sea surface warming. The large-scale surface wind anomaly is also linked to the decadal variation associated with the climate modes (PDO and NPGO) in the North Pacific.

Certainly, the underwater terrain, the variability of mixed layer depth, and other environmental factors are needed to further examine the eddy variability in the NEP. In addition, the eddy attenuation time scale is also related to the vertical scale of eddies (Gaube et al.2015), which means that further knowledge regarding the three-dimensional structures of ocean eddies is required to estimate the long-term trend of eddy activity. Besides that, the trend of normalized EKE shows increases in both the northeastern and southwestern triangles. We chose the southwestern triangle as our study domain to investigate the increases of eddy activity because both EKE and EON show positive linear trends in the study domain. The increase of EKE in the northeastern triangle and other spatial characteristics are not the foci of this paper and need further research.

In addition to the dynamic mechanism through the mechanical processes suggested in this study, there are additional processes that may affect eddy activities. Byrne et al. (2016) indicate that the mesoscale atmosphere-ocean coupling enhances the transfer of wind energy into the ocean on the negative wind stress gradient side because of the presence of the thermodynamic pathway, which can modify the mesoscale eddy field substantially. Moreover, as suggested by recent works (e.g., Zhang et al. 2013; Kimizuka et al. 2015), a poleward shift and strengthening of the surface westerly wind are projected, with a poleward shift of the wind maximum predicted to occur by the end of the twenty-first century. The net powering of the mesoscale field due to the thermodynamic pathway may also be a possible cause for the increasing trend of eddy activity in the NEP if the thermodynamic pathway in the NEP is important. Therefore, further analysis should be carried out to compare the relative importance of the dynamic and thermodynamic processes.

Acknowledgments. We thank Dr. Dudley B. Chelton and colleagues and Dr. James H. Faghmous and colleagues for sharing the global mesoscale eddy trajectory dataset. We acknowledge the helpful and encouraging comments from Drs. Ru Chen, Chuanyu Liu, and Baoxin Feng. This study is supported by National Key R\&D Program for Developing Basic Sciences (2016YFC1401401, 2016YFC1401601), the National Key Program for Developing Basic Sciences (Grant 2013CB956204), the "Strategic Priority Research Program" of the Chinese Academy of Sciences (Grant XDA11010304), and the National Natural Science Foundation of China (Grants 41576026, 41376019, and 41576025).

\section{REFERENCES}

Bond, N. A., J. E. Overland, M. Spillane, and P. Stabeno, 2003: Recent shifts in the state of the North Pacific. Geophys. Res. Lett., 30, 2183, https://doi.org/10.1029/2003GL018597.

Bryden, H. L., and E. C. Brady, 1989: Eddy momentum and heat fluxes and their effect on the circulation of the equatorial Pacific Ocean. J. Mar. Res., 47, 55-79, https://doi.org/10.1357/ 002224089785076389. 
Byrne, D., M. Münnich, I. Frenger, and N. Gruber, 2016: Mesoscale atmosphere ocean coupling enhances the transfer of wind energy into the ocean. Nat. Commun., 7, 11867, https://doi.org/ 10.1038/ncomms11867.

Chaigneau, A., M. L. Texier, G. Eldin, C. Grados, and O. Pizarro, 2011: Vertical structure of mesoscale eddies in the eastern South Pacific Ocean: A composite analysis from altimetry and Argo profiling floats. J. Geophys. Res., 116, C11025, https:// doi.org/10.1029/2011JC007134.

Chelton, D. B., and M. G. Schlax, 2013: Mesoscale eddies in altimeter observations of SSH. Accessed 2017, http:// wombat.coas.oregonstate.edu/eddies_May2013/.

- - , R. M. Samelson, and R. A. de Szoeke, 2007: Global observations of large oceanic eddies. Geophys. Res. Lett., 34, L15606, https://doi.org/10.1029/2007GL030812.

,-- , and — 2011: Global observations of nonlinear mesoscale eddies. Prog. Oceanogr., 91, 167-216, https://doi.org/ 10.1016/j.pocean.2011.01.002.

Cheng, Y.-H., C.-R. Ho, Q. Zheng, and N.-J. Kuo, 2014: Statistical characteristics of mesoscale eddies in the North Pacific derived from satellite altimetry. Remote Sens., 6, 5164-5183, https://doi.org/10.3390/rs6065164.

Chow, C. H., Y.-H. Tseng, H.-H. Hsu, and C.-C. Young, 2017: Interannual variability of the subtropical countercurrent eddies in the North Pacific associated with the western-Pacific teleconnection pattern. Cont. Shelf Res., 143, 175-184, https:// doi.org/10.1016/j.csr.2016.08.006.

Dee, D. P., and Coauthors, 2011: The ERA-Interim reanalysis: Configuration and performance of the data assimilation system. Quart. J. Roy. Meteor. Soc., 137, 553-597, https://doi.org/ 10.1002/qj.828.

DiGiacomo, P. M., and B. Holt, 2001: Satellite observations of small coastal ocean eddies in the Southern California Bight. J. Geophys. Res., 106, 22 521-22 543, https://doi.org/10.1029/ 2000JC000728.

Di Lorenzo, E., and Coauthors, 2008: North Pacific Gyre Oscillation links ocean climate and ecosystem change. Geophys. Res. Lett., 35, L08607, https://doi.org/10.1029/2007GL032838.

Ducet, N., P. Y. Le Traon, and G. Reverdin, 2000: Global highresolution mapping of ocean circulation from TOPEX/ Poseidon and ERS-1 and -2. J. Geophys. Res., 105, $19477-$ 19498, https://doi.org/10.1029/2000JC900063.

Faghmous, J. H., I. Frenger, Y. Yao, R. Warmka, A. Lindell, and V. Kumar, 2015: A daily global mesoscale ocean eddy dataset from satellite altimetry. Sci. Data, 2, 150028, https://doi.org/ 10.1038/sdata.2015.28.

Ferrari, R., and C. Wunsch, 2009: Ocean circulation kinetic energy: Reservoirs, sources, and sinks. Annu. Rev. Fluid Mech., 41, 253 282, https://doi.org/10.1146/annurev.fluid.40.111406.102139.

Freeman, E., and Coauthors, 2017: ICOADS release 3.0: A major update to the historical marine climate record. Int. J. Climatol., 37, 2211-2232, https://doi.org/10.1002/ joc. 4775 .

Frenger, I., N. Gruber, R. Knutti, and M. Münnich, 2013: Imprint of Southern Ocean eddies on winds, clouds and rainfall. Nat. Geosci., 6, 608-612, https://doi.org/10.1038/ngeo1863.

—, M. Münnich, N. Gruber, and R. Knutti, 2015: Southern Ocean eddy phenomenology. J. Geophys. Res. Oceans, 120, 7413-7449, https://doi.org/10.1002/2015JC011047.

Gaube, P., D. B. Chelton, R. M. Samelson, M. G. Schlax, and L. W. O'Neill, 2015: Satellite observations of mesoscale eddyinduced Ekman pumping. J. Phys. Oceanogr., 45, 104-132, https://doi.org/10.1175/JPO-D-14-0032.1.
Good, S. A., M. J. Martin, and N. A. Rayner, 2013: EN4: Quality controlled ocean temperature and salinity profiles and monthly objective analyses with uncertainty estimates. J. Geophys. Res. Oceans, 118, 6704-6716, https://doi.org/ 10.1002/2013JC009067.

Griffies, S. M., and Coauthors, 2015: Impacts on ocean heat from transient mesoscale eddies in a hierarchy of climate models. J. Climate, 28, 952-977, https://doi.org/10.1175/ JCLI-D-14-00353.1.

He, Y., J. Xie, and S. Cai, 2016: Interannual variability of winter eddy patterns in the eastern South China Sea. Geophys. Res. Lett., 43, 5185-5193, https://doi.org/10.1002/2016GL068842.

Henson, S. A., and A. C. Thomas, 2008: A census of oceanic anticyclonic eddies in the Gulf of Alaska. Deep-Sea Res. I, 55, 163-176, https://doi.org/10.1016/j.dsr.2007.11.005.

Hogg, A. M., and Coauthors, 2015: Recent trends in the Southern Ocean eddy field. J. Geophys. Res. Oceans, 120, 257-267, https://doi.org/10.1002/2014JC010470.

Itoh, S., and I. Yasuda, 2010: Characteristics of mesoscale eddies in the Kuroshio-Oyashio Extension region detected from the distribution of the sea surface height anomaly. J. Phys. Oceanogr., 40, 1018-1034, https://doi.org/10.1175/2009JPO4265.1.

Jayne, S. R., and J. Marotzke, 2002: The oceanic eddy heat transport. J. Phys. Oceanogr., 32, 3328-3345, https://doi.org/ 10.1175/1520-0485(2002)032<3328:TOEHT>2.0.CO;2.

Ji, J., C. Dong, B. Zhang, and Y. Liu, 2017: An oceanic eddy statistical comparison using multiple observational data in the Kuroshio Extension region. Acta Oceanol. Sin., 36, 1-7, https://doi.org/10.1007/s13131-016-0882-1.

Kelly, K. A., and Coauthors, 2010: Western boundary currents and frontal air-sea interaction: Gulf Stream and Kuroshio Extension. J. Climate, 23, 5644-5667, https://doi.org/10.1175/ 2010JCLI3346.1.

Kimizuka, M., F. Kobashi, A. Kubokawa, and N. Iwasaka, 2015: Vertical and horizontal structures of the North Pacific subtropical gyre axis. J. Oceanogr., 71, 409-425, https://doi.org/ 10.1007/s10872-015-0301-9.

Kurczyn, J. A., E. Beier, M. F. Lavín, and A. Chaigneau, 2012: Mesoscale eddies in the northeastern Pacific tropicalsubtropical transition zone: Statistical characterization from satellite altimetry. J. Geophys. Res., 117, C10021, https:// doi.org/10.1029/2012JC007970.

Liu, Y., and Coauthors, 2012: Eddy analysis in the subtropical zonal band of the North Pacific Ocean. Deep-Sea Res. I, 68, 54-67, https://doi.org/10.1016/j.dsr.2012.06.001.

Ma, X., and Coauthors, 2015: Distant influence of Kuroshio eddies on North Pacific weather patterns? Sci. Rep., 5, 17785, https:// doi.org/10.1038/srep17785.

_ _ and Coauthors, 2016: Western boundary currents regulated by interaction between ocean eddies and the atmosphere. Nature, 535, 533-537, https://doi.org/10.1038/nature18640.

Mantua, N. J., and S. R. Hare, 2002: The Pacific decadal oscillation. J. Oceanogr., 58, 35-44, https://doi.org/10.1023/ A:1015820616384.

Meredith, M. P., and A. M. Hogg, 2006: Circumpolar response of Southern Ocean eddy activity to a change in the Southern Annular Mode. Geophys. Res. Lett., 33, L16608, https://doi.org/10.1029/2006GL026499.

Nakamura, H., T. Sampe, Y. Tanimoto, and A. Shimpo, 2004: Observed associations among storm tracks, jet streams and midlatitude oceanic fronts. Earth's Climate: The OceanAtmosphere Interaction, Geophys. Monogr., Vol. 147, Amer. Geophys. Union, 329-345. 
Newman, M., and Coauthors, 2016: The Pacific decadal oscillation, revisited. J. Climate, 29, 4399-4427, https://doi.org/10.1175/ JCLI-D-15-0508.1.

Oka, E., and B. Qiu, 2012: Progress of North Pacific mode water research in the past decade. J. Oceanogr., 68, 5-20, https:// doi.org/10.1007/s10872-011-0032-5.

O'Neill, L., D. Chelton, and S. Esbensen, 2003: Observations of SST-induced perturbations of the wind stress field over the Southern Ocean on seasonal timescales. J. Climate, 16, 2340 2354, https://doi.org/10.1175/2780.1.

Patara, L., C. W. Böning, and A. Biastoch, 2016: Variability and trends in Southern Ocean eddy activity in $1 / 12^{\circ}$ ocean model simulations. Geophys. Res. Lett., 43, 4517-4523, https://doi.org/10.1002/2016GL069026.

Pegliasco, C., A. Chaigneau, and R. Morrow, 2015: Main eddy vertical structures observed in the four major eastern boundary upwelling systems. J. Geophys. Res. Oceans, 120, 60086033, https://doi.org/10.1002/2015JC010950.

Qiu, B., 1999: Seasonal eddy field modulation of the North Pacific subtropical countercurrent: TOPEX/Poseidon observations and theory. J. Phys. Oceanogr., 29, 2471-2486, https://doi.org/ 10.1175/1520-0485(1999)029<2471:SEFMOT>2.0.CO;2.

— , and S. Chen, 2005: Variability of the Kuroshio Extension jet, recirculation gyre, and mesoscale eddies on decadal time scales. J. Phys. Oceanogr., 35, 2090-2103, https://doi.org/ 10.1175/JPO2807.1.

, and _ 2010: Interannual variability of the North Pacific subtropical countercurrent and its associated mesoscale eddy field. J. Phys. Oceanogr., 40, 213-225, https://doi.org/10.1175/ 2009JPO4285.1.

—, and —, 2013: Concurrent decadal mesoscale eddy modulations in the western North Pacific subtropical gyre. J. Phys. Oceanogr., 43, 344-358, https://doi.org/10.1175/ JPO-D-12-0133.1.

Rayner, N. A., and Coauthors, 2003: Global analyses of sea surface temperature, sea ice, and night marine air temperature since the late nineteenth century. J. Geophys. Res., 108, 4407, https://doi.org/10.1029/2002JD002670.

Screen, J. A., N. P. Gillett, D. P. Stevens, G. J. Marshall, and H. K. Roscoe, 2009: The role of eddies in the Southern Ocean temperature response to the southern annular mode. J. Climate, 22, 806-818, https://doi.org/10.1175/ 2008JCLI2416.1.

Shen, M. L., Y. H. Tseng, S. Jan, C. C. Young, and M. D. Chiou, 2014: Long-term variability of the Kuroshio transport east of Taiwan and the climate it conveys. Prog. Oceanogr., 121, 6073, https://doi.org/10.1016/j.pocean.2013.10.009.

Small, R. J., and Coauthors, 2008: Air-sea interaction over ocean fronts and eddies. Dyn. Atmos. Oceans, 45, 274-319, https:// doi.org/10.1016/j.dynatmoce.2008.01.001.

Stammer, D., 1998: On eddy characteristics, eddy transports, and mean flow properties. J. Phys. Oceanogr., 28, 727-739, https:// doi.org/10.1175/1520-0485(1998)028<0727:OECETA $>2.0$. CO;2.

Sun, Z., Z. Zhang, W. Zhao, and J. Tian, 2016: Interannual modulation of eddy kinetic energy in the northeastern South China Sea as revealed by an eddy-resolving OGCM. J. Geophys. Res. Oceans, 121, 3190-3201, https://doi.org/ 10.1002/2015JC011497.
Sydeman, W. J., J. A. Santora, S. A. Thompson, B. Marinovic, and E. Di Lorenzo, 2013: Increasing variance in North Pacific climate relates to unprecedented ecosystem variability off California. Global Change Biol., 19, 1662-1675, https://doi.org/ 10.1111/gcb.12165.

Uehara, H., T. Suga, K. Hanawa, and N. Shikama, 2003: A role of eddies in formation and transport of North Pacific subtropical mode water. Geophys. Res. Lett., 30, 1705, https://doi.org/ 10.1029/2003GL017542.

Wang, S. D., Z. L. Liu, C. G. Pang, and H. Q. Liu, 2016: The decadally modulating eddy field in the upstream Kuroshio Extension and its related mechanisms. Acta Oceanol. Sin., 35, 9-17, https://doi.org/10.1007/s13131-015-0741-5.

Xiu, P., F. Chai, H. Xue, L. Shi, and Y. Chao, 2012: Modeling the mesoscale eddy field in the Gulf of Alaska. Deep-Sea Res. I, 63, 102-117, https://doi.org/10.1016/j.dsr.2012.01.006.

Xu, C., X. Zhai, and X. Shang, 2016: Work done by atmospheric winds on mesoscale ocean eddies. Geophys. Res. Lett., 43, 12 174-12 180, https://doi.org/10.1002/2016GL071275.

Xu, L., S. Xie, J. L. McClean, Q. Liu, and H. Sasaki, 2014: Mesoscale eddy effects on the subduction of North Pacific mode waters. J. Geophys. Res. Oceans, 119, 4867-4886, https://doi. org/10.1002/2014JC009861.

Yang, G., F. Wang, Y. Li, and P. Lin, 2013: Mesoscale eddies in the northwestern subtropical Pacific Ocean: Statistical characteristics and three-dimensional structures. J. Geophys. Res. Oceans, 118, 1906-1925, https://doi.org/10.1002/jgrc.20164.

, W. Yu, Y. Yuan, X. Zhao, F. Wang, G. Chen, L. Liu, and Y. Duan, 2015: Characteristics, vertical structures, and heat/ salt transports of mesoscale eddies in the southeastern tropical Indian Ocean. J. Geophys. Res. Oceans, 120, 6733-6750, https://doi.org/10.1002/2015JC011130.

Yang, Y., X. San Liang, B. Qiu, and S. Chen, 2017: On the decadal variability of the eddy kinetic energy in the Kuroshio Extension. J. Phys. Oceanogr., 47, 1169-1187, https://doi.org/ 10.1175/JPO-D-16-0201.1.

Yoshida, S., B. Qiu, and P. Hacker, 2011: Low-frequency eddy modulations in the Hawaiian Lee Countercurrent: Observations and connection to the Pacific decadal oscillation. J. Geophys. Res., 116, C12009, https://doi.org/10.1029/ 2011JC007286.

Zhai, X., H. L. Johnson, and D. P. Marshall, 2010: Significant sink of ocean-eddy energy near western boundaries. Nat. Geosci., 3, 608-612, https://doi.org/10.1038/ngeo943.

Zhang, D., T. N. Lee, W. E. Johns, C. Liu, and R. Zantopp, 2001: The Kuroshio east of Taiwan: Modes of variability and relationship to interior ocean mesoscale eddies. J. Phys. Oceanogr., 31, 1054-1074, https://doi.org/10.1175/ 1520-0485(2001)031<1054:TKEOTM >2.0.CO;2.

Zhang, X., J. A. Church, S. M. Platten, and D. Monselesan, 2013: Projection of subtropical gyre circulation and associated sea level changes in the Pacific based on CMIP3 climate models. Climate Dyn., 43, 131-144, https://doi.org/ 10.1007/s00382-013-1902-x.

Zhang, Z., W. Wang, and B. Qiu, 2014: Oceanic mass transport by mesoscale eddies. Science, 345, 322-324, https://doi.org/ 10.1126/science. 1252418 . 